\title{
The Inherited p53 Mutation in the Brazilian Population
}

\author{
Maria Isabel Achatz ${ }^{1}$ and Gerard P. Zambetti ${ }^{2}$ \\ ${ }^{1}$ Department of Oncogenetics, A.C. Camargo Cancer Center, São Paulo, SP, Brasil \\ ${ }^{2}$ Department of Pathology, St. Jude Children's Research Hospital, Memphis, Tennessee 38105 \\ Correspondence: gerard.zambetti@stjude.org
}

A common criticism of studying rare diseases is the often-limited relevance of the findings to human health. Here, we review $\sim 15$ years of research into an unusual germline TP53 mutation ( $p . \mathrm{R} 337 \mathrm{H}$ ) that began with its detection in children with adrenocortical carcinoma (ACC), a remarkably rare childhood cancer that is associated with poor prognosis. We have come to learn that the p.R337H mutation exists at a very high frequency in Southern and Southeastern Brazil, occurring in one of 375 individuals within a total population of $\sim 100$ million. Moreover, it has been determined that carriers of this founder mutation display variable tumor susceptibility, ranging from isolated cases of pediatric ACC to Li-Fraumeni or Li-Fraumeni-like (LFL) syndromes, thus representing a significant medical issue for this country. Studying the biochemical and molecular consequences of this mutation on p53 tumor-suppressor activity, as well as the putative additional genetic alterations that cooperate with this mutation, is advancing our understanding of how p53 functions in tumor suppression in general. These studies, which originated with a rare childhood tumor, are providing important information for guiding genetic counselors and physicians in treating their patients and are already providing clinical benefit.

$\mathrm{Pa}$ ediatric adrenocortical carcinoma (ACC) is a very rare cancer that is usually associated with germline TP53 mutations, often occurring within the context of $\mathrm{Li}$-Fraumeni syndrome (LFS) (Ribeiro et al. 2012). The incidence of childhood ACC in Southern Brazil is extraordinarily high and without precedent. In 2001, a study of pediatric ACC patients from this region and unselected for familial history of cancer were found to harbor the same germline missense mutation in TP53 (p.R337H) in 35 of the 36 cases (Ribeiro et al. 2001). In contrast to the vast majority of constitutional TP53 mutations associated with LFS, the p.R337H mutation does not fall within the DNA-binding domain (DBD) of the p53 protein, but in a structural motif (an $\alpha$-helix) that mediates the formation of p53 dimers (Fig. 1) (DiGiammarino et al. 2002). Based on these early data, the penetrance of ACC in p.R337H carriers was estimated to be 1:10 (Figueiredo et al. 2006), which is in sharp contrast to the normal incidence of one in three million in the general population. More detailed studies of Brazilian ACC patients showed that 23 of 30 families that harbored the germline p.R337H mutation were not associated with

Editors: Guillermina Lozano and Arnold J. Levine

Additional Perspectives on The p53 Protein available at www.perspectivesinmedicine.org

Copyright (C) 2016 Cold Spring Harbor Laboratory Press; all rights reserved; doi: 10.1101/cshperspect.a026195

Cite this article as Cold Spring Harb Perspect Med 2015;6:a026195 
M.I. Achatz and G.P. Zambetti

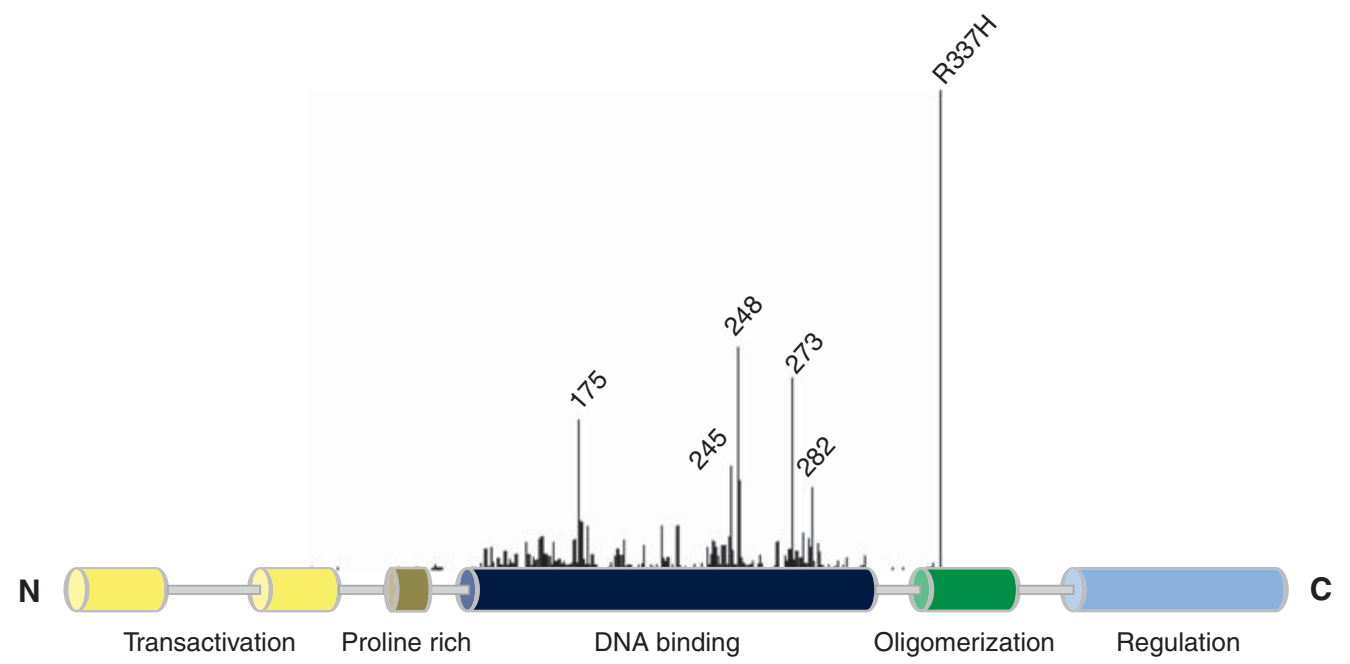

Figure 1.p53 structural domains and germline mutations associated with human cancers. Structural domains of p53 protein are schematically diagrammed. Cancer associated mutations (including the classical hotspot mutations) are identified according to the frequency and position within TP53. Note the high frequency of the constitutional p.R337H mutation common in Southern Brazil (see the International Agency for Research on Cancer [IARC] TP53 database, p53.iarc.fr) (Petitjean et al. 2007).

cancer (low risk), but that the remaining seven families could be classified as $\mathrm{Li}$-Fraumeni-like (LFL; occasional breast, brain, gastric tumors) (intermediate risk) (Ribeiro et al. 2001; Figueiredo et al. 2006).

Although germline TP53 mutations at codon 337 had been previously reported in the International Agency for Research on Cancer (IARC) database (Petitjean et al. 2007), nearly all were the missense mutation resulting in the arginine to cysteine substitution (R337C). The only exception was a 10 -year-old girl with brain cancer from the Institut Gustave Roussy in Paris, France, who was the first identified carrier of the p.R337H mutation (Chompret et al. 2000).

In the early 2000s, the development of oncogenetics practice in major cancer centers in Southeastern Brazil led to the frequent identification of families who fulfilled the criteria for LFS (Li et al. 1988) or LFL (Birch et al. 1994; Olivier et al. 2003). A subset of families with a less restricted family history of cancer, as defined by the Chompret criteria (Chompret et al. 2001), is also referred for TP53 mutation analysis and genetic counseling. Based on these clinical criteria, genetic testing identified seven of 45 probands as carriers of TP53 DBD mutations, typical of those most frequently associated with LFS/LFL (henceforth called "classic" or hotspot mutations) (Achatz et al. 2007). However, six of the 45 probands presented with p. $\mathrm{R} 337 \mathrm{H}$ and subsequent analyses of family members indicated that the mutation segregated with cancer risk. Interestingly, the proband carriers were adults who developed multiple cancers (Achatz et al. 2007). The spectrum of cancers occurring in p.R337H carriers resembled those of carriers of classic mutations, including the LFS-associated quartet of early soft tissue sarcomas, early onset breast cancer, cancers of the central nervous system, and childhood ACCs (Achatz et al. 2007). Since these initial studies, more than 180 individuals who are positive for the p.R337H mutation have been detected and followed up at oncogenetics cancer clinics throughout Southern Brazil. Careful assessment of the familial cancer patterns points to significant differences between Brazilian carriers of the p.R337H and classic TP53 mutations. First, the penetrance of cancer appears to be somewhat lower when only $15 \%-20 \%$ of the p.R337H carriers develop cancer by 30 years of age, compared 
with $\sim 50 \%$ in carriers of classic mutations. Second, ACC represents a greater proportion of all cancers in p. R337H carriers ( $~ 8 \%$ to $10 \%)$ than in carriers of classic mutations $(\sim 4 \%)$ (Kleihues et al. 1997). Third, whereas breast cancer was the most common malignancy diagnosed in carriers of the p.R337H and classic mutations, these cancers tended to occur at a slightly later median age in $\mathrm{p} . \mathrm{R} 337 \mathrm{H}$ ( 40 years) than in classic (32 years) carriers. Fourth, p.R337H carriers presented with a higher occurrence of papillary thyroid cancer in young adults, renal cancers, and lung adenocarcinomas than classic carriers. These results indicate that, although the familial presentation of cancer risk associated with p.R337H can clearly belong to the LFS spectrum, it shows specific traits that suggest it represents a variant of LFS.

Each of these earlier studies had inherent biases as a result of the context in which probands were selected, with, on the one hand, patients who had pediatric ACC with no striking a priori evidence of familial history, and on the other hand, mostly adult patients selected for familial history of cancer matching LFS/LFL criteria. Overall, these studies suggested that p.R337H might represent a deleterious variant highly prevalent in the Brazilian population, which could be associated with a highly heterogeneous level of risk of cancer. Indeed, an estimate of the prevalence of $\mathrm{p} . \mathrm{R} 337 \mathrm{H}$ in a population-based group of healthy women unselected for cancer history and participating in a breast cancer prevention study in the area of Porto Alegre, Rio Grande do Sul, found two carriers in a total of 750 subjects $(0.3 \%)$ (Palmero et al. 2008). To better estimate the impact of the mutation in the population of Southern Brazil, a simple PCR-based assay to detect the $337 \mathrm{H} \mathrm{mu}$ tation was developed and applied by Figueiredo and colleagues to screen 175,000 newborns in the State of Parana in Southern Brazil (Custódio et al. 2013). Key findings include (1) one in 375 individuals in Southern Brazil are carriers within a total population of $\sim 100$ million $(\sim 250$ 300,000 carriers); (2) the penetrance of childhood ACC is one in 30 to 40 rather than the initial estimate of one in 10 because of the elimination of the selection criteria, but still extraor-
Inherited p53 Mutation in the Brazilian Population

dinarily high; (3) families with carriers that are at low, intermediate, and high risk of cancer were identified; (4) three homozygous carriers were identified, each developed pediatric cancer (two ACC, and one choroid plexus carcinoma); and (5) screening combined with surveillance detected early stage tumors and improved outcome, thus providing clinical benefit (Custódio et al. 2013). A similar study was conducted in the region of Campinas, São Paulo, involving 35,000 newborns. A total of $0.21 \%$ of the population were found to be carriers of the p.R337H mutant (Caminha et al. 2015).

The extremely heterogeneous patterns of individual and familial cancer risk has led to the hypothesis that p.R337H may be an underlying factor in many cancers belonging to the LFS spectrum, but also contributing to tumor susceptibility in an apparently sporadic manner in the Brazilian population. Indeed, in a cohort of 815 women affected with breast cancer, unselected for familial history and recruited at three distinct hospital locations in Southern Brazil, the p.R337H mutation was detected in the germline of $12.1 \%$ of all patients who developed the disease before age 45 (Giacomazzi et al. 2015). Indeed, the high prevalence of p.R337H in the population of Southern Brazil and the heterogeneous patterns of risk suggest that this mutation may cause several thousand cancer cases every year in this population, only a fraction of which occur in a familial setting matching LFS/LFL definitions. The notion that individual risk is very heterogeneous is supported by the analysis of several large pedigrees showing that, within the same extended family group, some subclusters presented with a familial disease-matching strict LFS definition, whereas other subclusters of distant relatives had only few cancers, among which included pediatric ACC.

\section{GENETICS}

Initial studies on the genetic diversity of TP53 alleles in p. $\mathrm{R} 337 \mathrm{H}$ carriers were inconclusive and discounted the possibility of a common founder (Ribeiro et al. 2001). Subsequently, Pinto et al. (2004) established a founder effect for the p.R337H mutation using two intragenic 
hypervariable microsatellite markers. In 2010, Garritano and colleagues confirmed and extended these findings using a detailed set of 29 SNPs (single-nucleotide polymorphisms) localized throughout the 20-kb TP53 locus. They demonstrated that a group of 12 apparently unrelated carriers of the p.R337H mutation all shared the identical relatively rare haplotype of TP53 and that the allele was of European Caucasian ancestry. Furthermore, the first reported case of p.R337H in the child with adrenocortical cancer tested in France (see above), was a young girl of Portuguese origin who also carried the same TP53 haplotype (Chompret et al. 2000; Garritano et al. 2010). To date, all Brazilian p.R337H carriers who have been tested share the same founder allele. Significantly, this haplotype has also been found in a few carriers detected outside Brazil, including a patient treated in Portugal (a documented "reverse" Brazilian migrant) (Pinto et al. 2009) and two patients in the United States (both of documented Brazilian origin) (data not shown). Recently, a patient with a germline p.R337H mutation was identified in Germany (Herrmann et al. 2012). This patient, a male, who developed an ACC at age 71 and whose family history of cancer includes a father with prostate cancer (at 62 years of age) and a daughter with breast tumor at age 37, carried the mutation on a different haplotype than the Brazilian p.R337H carriers. It is, therefore, likely that this German patient represents a distinct, independent occurrence of the same mutation. It is important to note that the p.R337H mutation occurs at a CpG motif in the TP53 gene, a dinucleotide motif that is prone to spontaneous deamination and highly mutable. Therefore, the independent occurrence of the same mutation at this motif is not unexpected, making even more spectacular the unique founder haplotype detected in all Brazilian carriers.

The remarkable genetic homogeneity of TP53 haplotypes in p. R337H carriers raises the question of whether the wide heterogeneity in cancer risk is caused by genetic and/or lifestyle/ environmental factors. Marcel et al. (2009) and Sagne et al. (2014) analyzed whether TP53 SNPs may be associated with differences in age at first cancer onset in p.R337H carriers. The investigators have assumed that, because all carriers have the same mutant allele, SNPs on the other wild-type allele may affect p53 function and, therefore, cancer penetrance. They found that a common polymorphism consisting of a repeat of $16 \mathrm{bp}$ in TP53 intron 3 (rs17878362) was associated with a significant difference in age at first cancer onset. The mutant p.R337H allele carries one copy of the $16 \mathrm{bp}$ motif. Carriers of the p.R337H mutation and a wild-type TP53 allele containing a single copy of the 16 bp motif developed early (childhood) cancer, including ACC. In contrast, carriers with a wild-type allele containing two copies of the 16-bp motif developed only adult cancers, with no cases of ACC. The functional impact of this polymorphism on p53 activity is not fully understood. The polymorphism falls within a region that forms G-quadruplex structures in p53 pre-mRNA (Sagne et al. 2014). G-quadruplexes are secondary motifs involved in the regulation of mRNA stability, processing, and splicing, and there is experimental evidence that this polymorphism modulates p53 splicing. It is therefore tempting to speculate that the polymorphism may have an impact on the level of expression of wild-type p53 in the p.R337H carriers, resulting in different degrees of haploinsufficiency, depending on the nature of the wild-type haplotype.

\section{DEMOGRAPHY AND HISTORY}

To date, p.R337H carriers have been repeatedly detected throughout a region of Brazil extending from the State of Minas Gerais (Southern region of Brazil) to the State of Rio Grande do Sul (South region of Brazil), two regions that are separated by more than 2000 kilometers $(\sim 1500$ miles $)$. A recent study has identified the presence of the mutation in Paraguay, in populations residing along the Brazilian border (Legal et al. 2015). The region from Rio Grande do Sul to Minas Gerais in Brazil was settled by migrants of Portuguese origin during the late 17th and early 18th centuries. In particular, Southern Brazil was explored and settled by Portuguese immigrants in the first four decades of the 
1700s, opening and progressing along transit routes that became known as the "Tropeiro roads." Tropeiros were traveling merchants trading cattle and consumer goods between Southern Brazil and the metropolitan area of São Paulo. Introduction of a mutant allele of Portuguese origin may have occurred in the initial stages of the colonization of Southern Brazil at the time when the population was low and propagated by extensive dissemination along the main trade roads, enabling it to reach the significant prevalence in the current population (Garritano et al. 2010). However, it remains difficult to explain how a mutation associated with increased cancer risk, which is supposedly detrimental, has maintained itself over time at such a high frequency in a large population. The answer to this apparent paradox may lie in the heterogeneous pattern of risk associated with p.R337H, which may actually have prevented the reproduction of only a small subset of the carriers.

The historical premise for the p.R337H founder mutation is supported by the observation that the vast majority of carriers report themselves as being descendants of early Portuguese settlers, a circumstance documented by the genealogical records of a few large families. This demographic profile is not representative of the diversity of the current population of
Inherited p53 Mutation in the Brazilian Population

Southern Brazil, which has been impacted by successive waves of different European immigrant groups (Germans and Italians, in particular) during the second half of the 18th and the first half of the 19th century. However, this hypothesis has not been formally demonstrated. Of note, data are very scarce on the prevalence of p.R337H in central and Northern Brazil, Uruguay, or Argentina.

\section{BIOCHEMISTRY}

The p.R337H mutation is a consequence of a single nucleotide substitution at codon 337 $(\mathrm{CGC} \rightarrow \mathrm{CAC})$, resulting in the substitution of histidine for arginine. The mutation occurs at a CpG site and possibly arose because of spontaneous deamination. The p.R337H mutation impacts a salt bridge within the dimerization domain (Fig. 2), and structural studies revealed a pH-dependent nature of this mutation on $\mathrm{p} 53$ stability (DiGiammarino et al. 2002). The mutant protein is also susceptible to amyloid fiber formation, at least in vitro (Lee et al. 2003). Functional studies show that the p.R337H mutant retains significant activity (e.g., transactivation of promoter-reporters and endogenous target genes, cell-cycle arrest, apoptosis, and colony reduction) at a level comparable to
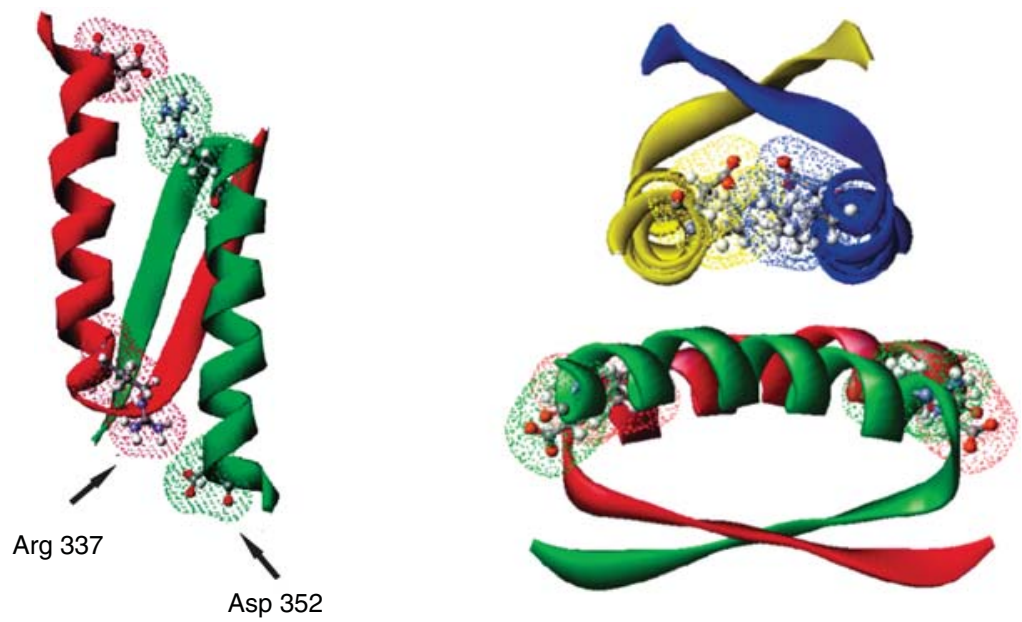

Figure 2. The p53 tetramerization domain. The stabilizing salt bridges involving Arg 337 and Asp 352 within the dimer (left) and tetramer (right) complexes are highlighted. (From DiGiammarino et al. 2002; reprinted, with permission, from the authors and Nature Publishing Group (C) 2002.) 
wild-type p53 when ectopically expressed in a variety of tissue culture cells (Ribeiro et al. 2001). In contrast, DNA-binding mutants that are commonly associated with LFS are completely inactive in these assays. Similar findings demonstrating significant transactivation function by the p.R337H mutant have been observed in yeast reporter studies (Kawaguchi et al. 2005). However, the adrenocortical tumors undergo chromosome $17 \mathrm{LOH}$ ([loss of heterozygosity] deletion of the wild-type p53 allele) and express high levels of the missense protein in the nucleus (Ribeiro et al. 2001). Intuitively, the endogenous p.R337H mutant must be functionally inactive in these tumors when physiologically expressed.

The findings that the p.R337H mutant retains substantial function compared with the DNA-binding mutants, at least in the in vitro assays, is consistent with many carriers remaining tumor-free. The unique $\mathrm{pH}$-dependent nature of this mutation may be influenced by the physiology of the adrenal cortex during development. During embryogenesis, the adrenal cortex plays an important role in maintaining the function and integrity of the placenta and rapidly expands to become adult size. Shortly after birth, the cortex reorganizes and regresses because of the activation of apoptosis, and loses $\sim 50 \%$ of its weight (Bland et al. 2003). We speculate that an adrenocortical cell that was destined to stop dividing during embryogenesis or to die shortly after birth continues to proliferate and survive, resulting in tumors 2 to 3 years later, consistent with the peak age of children who develop ACC. The incomplete penetrance of p. $\mathrm{R} 337 \mathrm{H}$ in promoting ACC may be related to the mutant not forming stable dimers/tetramers with wild-type p53 (DiGiammarino et al. 2002) and therefore not functioning as a dominant negative. The multihit nature of adrenocortical tumors requiring additional genetic alterations for tumorigenesis (e.g., chromosome 11p15 and $17 \mathrm{LOH}$ and amplification of chromosome 9q34) (Pinto et al. 2015) may also limit penetrance.

Whether the p.R337H mutation alters the extensive posttranslational modifications that normally take place during the activation of endogenous p53 in response to cell stress (e.g., phosphorylation of S15, S20, and acetylation of key lysines within the DBD and carboxyl terminus) remains to be determined. Similarly, changes in associated proteins, such as MDM2, p300/CBP, and transcription associated factors (TAFs), must also be addressed to better understand how p.R337H function may be affected in a physiologic manner in human tumors.

\section{CLINICAL CONSIDERATIONS}

An important lesson learned from the adrenal tumor studies is that not all germline TP53 mutations are equivalent in inactivating tumor-suppressor function (Ribeiro et al. 2012). Some are catastrophic and completely disrupt DNA binding, such as p.R175H. This particular mutant creates a $\mathrm{Zn}$ finger that inappropriately binds zinc, causing improper folding and a complete loss of DNA-binding and tumor-suppressor activity. Individuals who inherit this particular p53 "conformation" mutation are at a remarkably high risk of developing cancer (diverse tumor spectrum, multiple tumors, and early onset). In contrast, the p.R175L mutant retains partial activity in cell-based assays and individuals who inherit this mutation are at an apparent lower risk of cancer (West et al. 2006). These examples illustrate how different amino acid substitutions at a single site can have very different effects on p53 structure and function and, consequently, on clinical outcome (Zambetti 2007). The significantly shorter time to tumor onset in the homozygous p.R172H (equivalent to human p.R175H) knockin mutant p53 mice compared with the p.R172P mutant mice convincingly bears this concept out in a genetically defined animal model (Liu et al. 2000).

In the case of the p.R337H mutation in Southern Brazil, there is a spectrum of tumor susceptibility in families associated with this germline mutation (Fig. 3). In these cases, the individuals all carry the same founder mutation, but some are at high risk of breast, brain, and gastric cancers, for example, whereas others are at low risk of cancer and survive to older ages tumor-free (e.g., one individual $>100$ years). We speculate that the high-risk families have secondary genetic alterations that cooperate 
$\&_{2 \mathrm{CSH}}^{\infty} \&$ Cold Spring Harbor Perspectives in Medicine

PERSPECTIVES www.perspectivesinmedicine.org

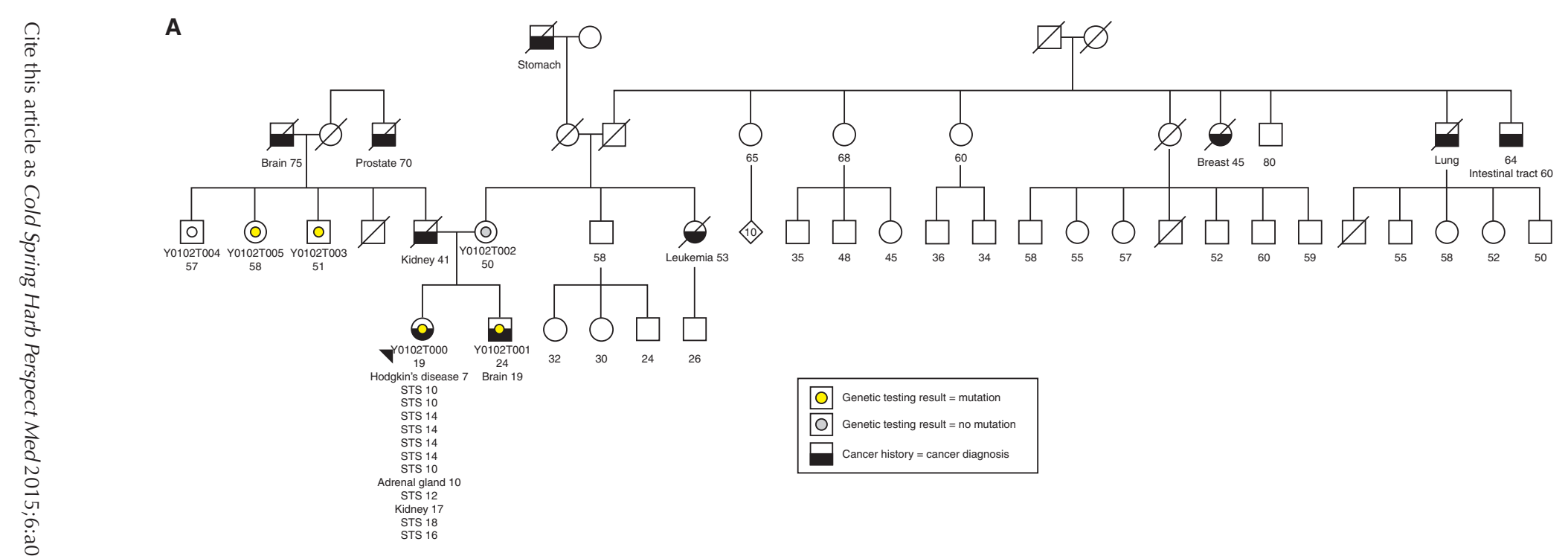

B

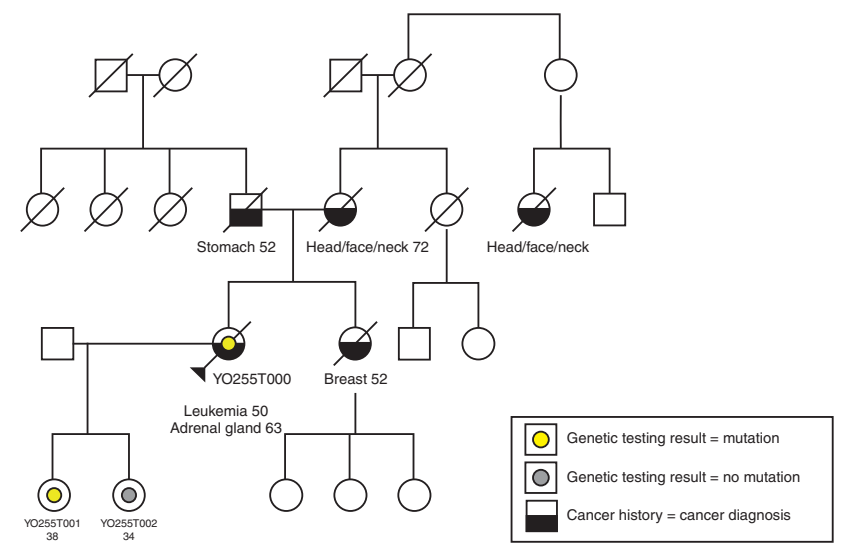

Figure 3. Pedigrees of high-risk Brazilian family associated with germline TP53-R337H mutation. 
with the p.R337H mutation. Identification of these cooperating mutations will be important for genetic counseling purposes and for developing long-term clinical follow-up plans for carriers of germline p.R337H.

Whole-genome sequencing of a cohort of Brazilian pediatric ACCs associated with the germline p.R337H mutation revealed $\mathrm{LOH}$ of the entire chromosome 17 in every case, always selecting against the wild-type allele. More detailed analyses show that chromosome $17 \mathrm{LOH}$ occurs early during tumorigenesis, consistent with it being a driver event (Pinto et al. 2015). As a consequence of losing wild-type p53 function, the tumors were expected to display chromosomal instability. However, a spectrum of genetic alterations was observed, ranging from very quiet genomes to tumors encountering massive chromosomal alterations, including large deletions, amplifications, and rearrangements. Those tumors with the highest degree of genomic instability were associated with somatic mutations in ATRX, which encodes a helicase that functions in chromatin remodeling and telomere maintenance. Perhaps not too surprisingly, these tumors correlated with the worst prognosis. The identification of mutations that cooperate with p.R337H during tumorigenesis, such as ATRX, will be important for advancing our understanding of adrenocortical tumor biology, which hopefully will lead to new and improved treatments for this aggressive childhood cancer.

\section{FUTURE PROSPECTS}

Whole-genome sequencing offers the hope of identifying polymorphisms and other constitutional genetic alterations that influence tumor susceptibility in carriers of the p.R337H mutation. Genetically engineered mouse models with the equivalent germline p.R337H allele (p.R334H) are expected to advance our understanding of how this mutation alters p53 responses in a physiological manner. Whether the p.R337H mutation will selectively compromise responses to some cellular stresses (e.g., DNA damage, hyperproliferation, and hypoxia) but not others, and whether cell-fate outcomes (e.g., cell-cycle arrest, apoptosis, senescence, DNA repair, metabolism) will be differentially affected in a tissue-specific manner will be important to determine. These efforts may shed light onto why childhood adrenocortical tumors are so prevalent in families with a constitutional p.R337H mutation. The establishment of induced pluripotent stem cells from carriers of the Brazilian p.R337H mutation also holds great potential for studying the functional consequence of this mutation on p53 in a physiological manner.

Neonatal screening for the p.R337H mutation in Southern Brazil has had clinical benefit for carriers whom are monitored for early signs of pediatric adrenocortical tumors (Custódio et al. 2013). Screening for other malignancies, in particular breast and brain cancers, may also bring clinical benefit for p.R337H mutation carriers. Finally, advancing our understanding of how p53 functions and the cooperating genetic alterations that influence tumor susceptibility will be essential for guiding geneticists in counseling their patients and for improving the clinical management of carriers of LFS/LFLassociated and low-penetrant germline TP53 mutations.

\section{REFERENCES}

Achatz MI, Olivier M, Le Calvez F, Martel-Planche G, Lopes A, Rossi BM, Ashton-Prolla P, Giugliani R, Palmero EI, Vargas FR, et al. 2007. The TP53 mutation, $\mathrm{R} 337 \mathrm{H}$, is associated with $\mathrm{Li}-\mathrm{Fraumeni}$ and $\mathrm{Li}-\mathrm{Frau}-$ meni-like syndromes in Brazilian families. Cancer Lett 245: 96-102.

Birch JM, Hartley AL, Tricker KJ, Prosser J, Condie A, Kelsey AM, Harris M, Jones PHM, Binchy A, Crowther D, et al. 1994. Prevalence and diversity of constitutional mutations in the p53 gene among $21 \mathrm{Li}-$ Fraumeni families. Cancer Res 54: 1298-1304.

Bland ML, Desclozeaux M, Ingraham HA. 2003. Tissue growth and remodeling of the embryonic and adult adrenal gland. Ann NY Acad Sci 995: 59-72.

Caminha IP. 2015. "Prevalence of TP53 germline mutation p.R337H in the metropolitan region of Campinas and surrounding cities. Campinas-SP." PhD thesis, Universidade Estadual de Campinas (UNICAMP), Campinas-SP, Brasil.

Chompret A, Brugières L, Ronsin M, Gardes M, DessarpsFreichey F, Abel A, Hua D, Ligot L, Dondon MG, Bressacde Paillerets B, et al. 2000. P53 germline mutations in childhood cancers and cancer risk for carrier individuals. Br J Cancer 82: 1932-1937. 
Chompret A, Abel A, Stoppa-Lyonnet D, Brugiéres L, Pagés S, Feunteun J, Bonaïti-Pellié C. 2001. Sensitivity and predictive value of criteria for $p 53$ germline mutation screening. J Med Genet 38: 43-47.

Custódio G, Parise GA, Kiesel Filho N, Komechen H, Sabbaga CC, Rosati R, Grisa L, Parise I, Pianovski MA, Fiori C, et al. 2013. Impact of neonatal screening and surveillance for the TP53 R337H mutation on early detection of childhood adrenocortical tumors. JClin Oncol 31: 26192626.

DiGiammarino EL, Lee AS, Cadwell C, Zhang W, Bothner B, Ribeiro RC, Zambetti GP, Kriwacki RW. 2002. A novel mechanism of tumorigenesis involving $\mathrm{pH}$-dependent destabilization of a mutant p53 tetramer. Nat Struct Biol 9: 12-16.

Figueiredo BC, Sandrini R, Zambetti GP, Pereira RM, Cheng C, Lacerda L, Pianovski MA, Michalkiewicz E, Jenkins J, Rodriguez-Galindo C, et al. 2006. Penetrance of adrenocortical tumors associated with the germline TP53 R337H mutation. J Med Genet 43: 91-96.

Garritano S, Gemignani F, Palmero EI, Olivier M, MartelPlanche G, Le Calvez-Kelm F, Brugiéres L, Vargas FR, Brentani RR, Ashton-Prolla P, et al. 2010. Detailed haplotype analysis at the TP53 locus in p.R337H mutation carriers in the population of Southern Brazil: Evidence for a founder effect. Hum Mutat 31: 143-150.

Giacomazzi J, Graudenz MS, Osorio CA, Koehler-Santos P, Palmero EI, Zagonel-Oliveira M, Michelli RA, Scapulatempo Neto C, Fernandes GC, Achatz MI, et al. 2014 Prevalence of the TP53 p.R337H mutation in breast cancer patients in Brazil. PLoS ONE 9: e99893.

Herrmann LJ, Heinze B, Fassnacht M, Willenberg HS, Quinkler M, Reisch N, Zink M, Allolio B, Hahner S. 2012 TP53 germline mutations in adult patients with adrenocortical carcinoma. J Clin Endocrinol Metab 97: e476e485.

Kawaguchi T, Kato S, Otsuka K, Watanabe G, Kumabe T, Tominaga T, Yoshimoto T, Ishioka C. 2005. The relationship among p53 oligomer formation, structure and transcriptional activity using a comprehensive missense mutation library. Oncogene 24: 6976-6981.

Kleihues P, Schäuble B, zur Hausen A, Estève J, Ohgaki H. 1997. Tumors associated with $p 53$ germline mutations: A synopsis of 91 families. Am J Pathol 150: 1-13.

Lee AS, Galea C, DiGiammarino EL, Jun B, Murti G, Ribeiro RC, Zambetti G, Schultz CP, Kriwacki RW. 2003. Reversible amyloid formation by the p53 tetramerization domain and a cancer-associated mutant. J Mol Biol 327: 699-709.

Legal EF, Ascurra M, Custódio G, Ayala HL, Monteiro M, Vega C, Fernández-Nestosa MJ, Vega S, Sade ER, Coelho IM, et al. 2015. Prevalence of an inherited cancer predisposition syndrome associated with the germ line TP53 R337H mutation in Paraguay. Cancer Epidemiol 39: 166169.

Li FP, Fraumeni JF Jr, Mulvihill JJ, Blattner WA, Dreyfus MG, Tucker MA, Miller RW. 1988. A cancer family syndrome in twenty-four kindreds. Cancer Res 48: 5358-5362.

Liu G, McDonnell TJ, Montes de Oca Luna R, Kapoor M, Mims B, El-Naggar AK, Lozano G. 2000. High metastatic
Inherited p53 Mutation in the Brazilian Population

potential in mice inheriting a targeted p53 missense mutation. Proc Natl Acad Sci 97: 4174-4179.

Marcel V, Palmero EI, Falagan-Lotsch P, Martel-Planche G, Ashton-Prolla P, Olivier M, Brentani RR, Hainaut P, Achatz MI. 2009. TP53 PIN3 and MDM2 SNP309 polymorphisms as genetic modifiers in the Li-Fraumeni syndrome: Impact on age at first diagnosis. J Med Genet 46: 766-772.

Olivier M, Goldgar DE, Sodha N, Ohgaki H, Kleihues P, Hainaut P, Eeles RA. 2003. Li-Fraumeni and related syndromes: Correlation between tumor type, family structure, and TP53 genotype. Cancer Res 63: 6643-6650.

Palmero EI, Schüler-Faccini L, Caleffi M, Achatz MI, Olivier M, Martel-Planche G, Marcel V, Aguiar E, Giacomazzi J, Ewald IP, et al. 2008. Detection of R337H, a germline TP53 mutation predisposing to multiple cancers, in asymptomatic women participating in a breast cancer screening program in Southern Brazil. Cancer Lett 261: 21-25.

Petitjean A, Mathe E, Kato S, Ishioka C, Tavtigian SV, Hainaut P, Olivier M. 2007. Impact of mutant p53 functional properties on TP53 mutation patterns and tumor phenotype: Lessons from recent developments in the IARC TP53 database. Hum Mutat 28: 622-629.

Pinto EM, Billerbeck AE, Villares MC, Domenice S, Mendonça BB, Latronico AC. 2004. Founder effect for the highly prevalent $\mathrm{R} 337 \mathrm{H}$ mutation of tumor suppressor p53 in Brazilian patients with adrenocortical tumors. Arq Bras Endocrinol Metabol 48: 647-650.

Pinto C, Veiga I, Pinheiro M, Peixoto A, Pinto A, Lopes JM, Reis RM, Oliveira C, Baptista M, Roque L, et al. 2009. TP53 germline mutations in Portugal and genetic modifiers of age at cancer onset. Familial Cancer 8: 383-390.

Pinto EM, Chen X, Easton J, Finkelstein D, Liu Z, Pounds S, Rodriguez-Galindo C, Lund TC, Mardis ER, Wilson RK, et al. 2015. Genomic landscape of paediatric adrenocortical tumours. Nat Commun 6: 6302.

Ribeiro RC, Sandrini F, Figueiredo B, Zambetti G, Lafferty AR, DeLacerda L, Baer C, Cadwell RC, Sampaio G, Cat I, et al. 2001. Childhood adrenal cortical tumors in southern Brazil are associated with a novel germline $p 53 \mathrm{mu}-$ tation. Proc Nat Acad Sci 98: 9330-9335.

Ribeiro RC, Pinto EM, Zambetti GP, Rodriguez-Galindo C. 2012. The International Pediatric Adrenocortical Tumor Registry initiative: Contributions to clinical, biological, and treatment advances in pediatric adrenocortical tumors. Mol Cell Endocrinol 351: 37-43.

Sagne C, Marcel V, Bota M, Martel-Planche G, Nobrega A, Palmero EI, Perriaud L, Boniol M, Vagner S, Cox DG, et al. 2014. Age at cancer onset in germline TP53 mutation carriers: Association with polymorphisms in predicted G-quadruplex structures. Carcinogenesis 35: 807-815.

West AN, Ribeiro RC, Jenkins J, Rodriguez-Galindo C, Figueiredo BC, Kriwacki R, Zambetti GP. 2006. Identification of a novel germ line variant hotspot mutant p53R175L in pediatric adrenal cortical carcinoma. Cancer Res 66: 5056-5062.

Zambetti GP. 2007. The p53 mutation "gradient effect" and its clinical implications. J Cell Physiol 213: 370-373. 


\title{
$\& \mathrm{CSH} \&$ Cold Spring Harbor

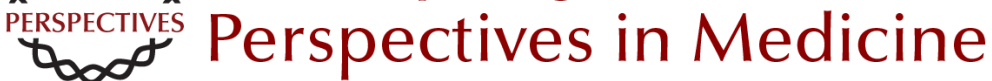

\section{The Inherited p53 Mutation in the Brazilian Population}

\author{
Maria Isabel Achatz and Gerard P. Zambetti \\ Cold Spring Harb Perspect Med 2016; doi: 10.1101/cshperspect.a026195 originally published online \\ September 23, 2016
}

\section{Subject Collection The p53 Protein}

Targeting the MDM2-p53 Protein-Protein Interaction for New Cancer Therapy: Progress and Challenges

Shaomeng Wang, Yujun Zhao, Angelo Aguilar, et al.

Structural Evolution and Dynamics of the p53

Proteins

Giovanni Chillemi, Sebastian Kehrloesser,

Francesca Bernassola, et al.

Exploiting the p53 Pathway for Therapy

Chit Fang Cheok and David Philip Lane

The Regulation of Cellular Functions by the p53 Protein: Cellular Senescence

Crystal A. Tonnessen-Murray, Guillermina Lozano and James G. Jackson

The Transactivation Domains of the p53 Protein Nitin Raj and Laura D. Attardi

The Evolution of the Ribosomal Protein-MDM2p53 Pathway

Chad Deisenroth, Derek A. Franklin and Yanping Zhang

Somatic TP53 Mutations in the Era of Genome

Sequencing

Pierre Hainaut and Gerd P. Pfeifer

The Paradox of p53: What, How, and Why? Yael Aylon and Moshe Oren
Control of Cellular Aging, Tissue Function, and Cancer by p53 Downstream of Telomeres Caitlin M. Roake and Steven E. Artandi

Inherited TP53 Mutations and the Li -Fraumeni Syndrome

Tanya Guha and David Malkin

TP53 Mutations in Hypodiploid Acute Lymphoblastic Leukemia

Evan Q. Comeaux and Charles G. Mullighan

Transcriptional Regulation by Wild-Type and

Cancer-Related Mutant Forms of p53

Neil T. Pfister and Carol Prives

The Inherited p53 Mutation in the Brazilian Population

Maria Isabel Achatz and Gerard P. Zambetti

TP53 Mutations in Breast and Ovarian Cancer Laxmi Silwal-Pandit, Anita Langerød and Anne-Lise Børresen-Dale

p53 and the Carcinogenicity of Chronic Inflammation

Andrei V. Gudkov and Elena A. Komarova

Oncogenic Mutant p53 Gain of Function

Nourishes the Vicious Cycle of Tumor

Development and Cancer Stem-Cell Formation

Yoav Shetzer, Alina Molchadsky and Varda Rotter

For additional articles in this collection, see http://perspectivesinmedicine.cshlp.org/cgi/collection/ 